\title{
Association between food intake and obesity in pregnant women living with and without HIV in Cape Town, South Africa: a prospective cohort study
}

Hlengiwe P. Madlala1*, Nelia P. Steyn², Emma Kalk³, Mary-Anne Davies ${ }^{3,4}$, Dorothy Nyemba ${ }^{1,3}$, Thokozile R. Malaba', Ushma Mehta ${ }^{3}$, Gregory Petro ${ }^{5}$, Andrew Boulle ${ }^{3,4}$ and Landon Myer ${ }^{1}$

\begin{abstract}
Background: Although global nutrition/dietary transition resulting from industrialisation and urbanisation has been identified as a major contributor to widespread trends of obesity, there is limited data in pregnant women, including those living with HIV in South Africa. We examined food-based dietary intake in pregnant women with and without HIV at first antenatal care (ANC) visit, and associations with maternal overweight/obesity and gestational weight gain (GWG).

Methods: In an urban South African community, consecutive women living with $(n=479)$ and without $(n=510)$ HIV were enrolled and prospectively followed to delivery. Interviewer-administered non-quantitative food frequency questionnaire was used to assess dietary intake (starch, protein, dairy, fruits, vegetables, legumes, oils/fats) at enrolment. Associations with maternal body mass index (BMI) and GWG were examined using logistic regression models.

Results: Among women (median age 29 years, IQR 25-34), the prevalence of obesity (BMI $\geq 30 \mathrm{~kg} / \mathrm{m}^{2}$ ) at first ANC was $43 \%$ and that of excessive GWG (per IOM guidelines) was 37\% overall; HIV prevalence was 48\%. In women without HIV, consumption of potato (any preparation) (aOR 1.98, 95\% Cl 1.02-3.84) and pumpkin/butternut (aOR $2.13,95 \% \mathrm{Cl} 1.29-3.49)$ for $1-3$ days a week increased the odds of overweight/obesity compared to not consuming any; milk in tea/coffee (aOR 6.04,95\% Cl 1.37-26.50) increased the odds of excessive GWG. Consumption of eggs (any) (aOR $0.52,95 \% \mathrm{Cl} 0.32-0.86$ ) for $1-3$ days a week reduced the odds of overweight/obesity while peanut and nuts consumption for 4-7 days a week reduced the odds (aOR 0.34, 95\% Cl 0.14-0.80) of excessive GWG. In women with HIV, consumption of milk/yoghurt/maas to drink/on cereals (aOR 0.35, 95\% Cl 0.18-0.68), tomato (raw/cooked) (aOR 0.50, 95\% Cl 0.30-0.84), green beans (aOR 0.41, 95\% Cl 0.20-0.86), mixed vegetables (aOR 0.49, $95 \% \mathrm{Cl} 0.29-0.84$ ) and legumes e.g. baked beans, lentils (aOR 0.50, 95\% Cl 0.28-0.86) for 4-7 days a week reduced the odds of overweight/obesity; tomato (raw/cooked) (aOR $0.48,95 \% \mathrm{Cl} 0.24-0.96$ ) and mixed vegetables (aOR 0.38 , 95\% Cl 0.18-0.78) also reduced the odds of excessive GWG.
\end{abstract}

\footnotetext{
* Correspondence: hlengiwe.madlala@uct.ac.za

'Division of Epidemiology and Biostatistics, School of Public Health and Family Medicine, University of Cape Town, Falmouth Building, Anzio Road, Observatory, Cape Town, Western Cape 7925, South Africa

Full list of author information is available at the end of the article
}

C The Author(s). 2021 Open Access This article is licensed under a Creative Commons Attribution 4.0 International License, which permits use, sharing, adaptation, distribution and reproduction in any medium or format, as long as you give appropriate credit to the original author(s) and the source, provide a link to the Creative Commons licence, and indicate if changes were made. The images or other third party material in this article are included in the article's Creative Commons licence, unless indicated otherwise in a credit line to the material. If material is not included in the article's Creative Commons licence and your intended use is not permitted by statutory regulation or exceeds the permitted use, you will need to obtain permission directly from the copyright holder. To view a copy of this licence, visit http://creativecommons.org/licenses/by/4.0/ The Creative Commons Public Domain Dedication waiver (http://creativecommons.org/publicdomain/zero/1.0/) applies to the data made available in this article, unless otherwise stated in a credit line to the data. 
Conclusions: Diet modification may promote healthy weight in pregnant women living with and without HIV.

Keywords: Food intake, Body mass index, Gestational weight gain, Pregnancy, HIV,

\section{Introduction}

One of the targets for Sustainable Development Goal (SDG) 3 is 'reducing by one third premature mortality from non-communicable diseases (NCDs) through prevention and treatment'. In South Africa, almost 70\% of women over 15 years are overweight/obese, the highest prevalence in sub-Saharan Africa (SSA) [1]. Consequently, over $40 \%$ of pregnant women are obese at antenatal care (ANC) entry, including those living with human immunodeficiency virus (HIV) on lifelong antiretroviral therapy (ART) [2-5]. Abundant data show that maternal obesity is associated with metabolic complications in pregnancy, which later increase the risk of a range of NCDs during postpartum period [6-8]. Further, maternal obesity is associated with adverse birth outcomes and is implicated in foetal 'metabolic programming', which over time may be associated with metabolic complications in offspring [9-11]. Therefore, efforts directed at reducing obesity in pregnancy may have a significant impact in achieving some targets of SDG 3 by 2030 .

Global nutrition/dietary transition as a result of industrialisation and urbanisation has been identified as a major contributor to widespread trends of obesity [12]. Specifically, consumption of high calorie-rich foods which have poor micronutrient content has been shown to be associated with overweight/obesity [13]. In an urban setting in South Africa, mapping of household food environments revealed a large proportion $(71 \%)$ of households that frequently consume obesity-risky foods such as bread and processed meat, and low consumption (16\%) of protective foods such as fruits and vegetables [14]. Although several studies have reported dietary intake in South Africa [15-17], there is limited data in pregnant women, including those living with HIV.

During pregnancy, there is increased demand for nutrient supply to support the growth and development of the foetus, thus dietary intake of pregnant women may be different from the general population. Additionally, African women have a cultural belief of needing to 'eat for two' during pregnancy, which may increase the risk of excessive gestational weight gain (GWG) and subsequent postpartum NCDs in mothers and their children [18]. Therefore, research on dietary food intake in pregnant women is critical for the mission of curbing NCDs, particularly because diet is a modifiable lifestyle factor. The objective of the present study was to examine food-based dietary intake in pregnant women with and without HIV at first ANC visit in Cape Town, and associations with maternal obesity and GWG.

\section{Methods}

Consecutive pregnant women ( $\geq 18$ years) attending first ANC services at a large primary health care facility, Gugulethu Community Health Centre, were enrolled into a prospective cohort ( $n=989$, with HIV $[n=479]$ and without HIV $[n=510]$ ) between January 2017 and July 2018 and followed through to delivery (February 2019). For the study, participants were actively followed through face-to-face interviews with intensive measurements that took place during the first, second and third trimesters of pregnancy.

A 30-item non-quantitative Food Frequency Questionnaire (FFQ) was employed to assess dietary intake in the past 7 days prior to first ANC visit. To minimise burden on study participants, a 61-item FFQ designed for use in South African context $[19,20]$ was adapted to 30 -items assessed in this study. The limited food items included were selected because they are amongst the most commonly consumed in each of the food groups examined in the parent questionnaire. Although the parent FFQ has not been previously used in pregnant women, we have no reason to believe that the food items assessed necessarily change substantially in pregnancy other than the portion sizes which were not investigated in this study. The 30 food items assessed included 7 food groups, namely starch (brown/whole wheat bread/rolls, breakfast cereal [instant], oats porridge, sweet potato and potato [any preparation]), protein (red meat [any], organ meat e.g. liver, chicken [any], tinned fish and eggs [any]), dairy (milk/yoghurt/maas to drink/on cereals, milk in tea/coffee and cheese [except cottage]), fruits (citrus fruit e.g. orange, pure orange/guava juice, banana, mangoes, apples/pears and avocado), vegetables (broccoli, spinach [including morogo], carrots, tomato [raw/ cooked], green beans, green peas, mixed vegetables, pumpkin/butternut), legumes (legumes e.g. baked beans, lentils and peanut and nuts) and fats/oils (soft margarine [tub]). There were four responses to frequency of consumption - 'never', ' $1-3$ days', ' $4-6$ days' and ' 7 days'. In analysis, category ' 7 days' was combined with ' $4-6$ days' resulting in three categories with a third category named '4-7 days'.

Alcohol use in pregnancy was defined as alcohol consumption after finding out about the pregnancy. Socioeconomic status (SES) was represented as a composite 
score based on education level, employment status, type of housing, and presence of a toilet, running water, electricity, fridge, telephone and television in the house [21]; the scores were categorised into tertiles corresponding to lowest, middle and highest SES group. The study protocol was reviewed and approved by the Faculty of Health Sciences Human Research Ethics Committee of the University of Cape Town (REF 541/2015) and the Western Cape Department of Health (REF WC 2016RP6_286). Written informed consent was obtained from all participants at enrolment and all procedures complied with the Helsinki Declaration as revised in 1983.

\section{Outcome assessment}

Outcomes of the study were maternal BMI and GWG. At first ANC, which coincided with enrolment, weight and height measurements were performed by a trained study nurse using a calibrated scale (Charder, Taichung City, Taiwan) accurate to within $0.5 \mathrm{~kg}$; height measurements were taken to the nearest $0.1 \mathrm{~cm}$ using a stadiometer (Seca, Birmingham, United Kingdom). Using a method described by Santos et al. [22], a correction factor on weight measured at first ANC visit was applied based on gestational age (GA) at measurement. Briefly, using international standards for GWG in pregnancy [22], the median weight gained for each week of gestation was subtracted from the weight measured at first ANC visit based on BMI category. Using this corrected weight, the estimated BMI was then calculated as weight divided by squared height; and categorised as underweight (<18.5), normal (18.5-24.9), overweight (25$29.9)$ and obese $(\geq 30)$ in $\left.\mathrm{kg} / \mathrm{m}^{2}\right)$. Due to small percentage of underweight women, this category was combined with normal BMI in the regression. Further, in the regression, overweight and obese categories were combined for simplicity. For GWG, second and third trimester weight measurements were taken subsequent to the enrolment weight. Weekly maternal GWG was calculated by dividing the weight change between enrolment and second or third study visit by the number of weeks elapsed between the two intervals [23], and expressed as kg/week. Weekly GWG was categorised as inadequate, adequate and excessive based on the Institute of Medicine (IOM)-recommended GWG ranges which vary by BMI category [24].

\section{Statistical analysis}

Data were analysed using STATA version 15.0 (Stata Corporation, College Station, TX, USA). Maternal baseline characteristics and frequency of food-based dietary consumption were stratified by HIV status, BMI and GWG categories. Differences between groups were compared using Chi-Squared test. Associations between the frequency of consumption of the 30 individual food items and maternal BMI as well as GWG in women with and without HIV were examined using multivariable logistic regression models. Results are presented as adjusted odds ratios (aOR) with related 95\% confidence intervals (CI). Adjusted models included a priori confounders such as age, SES, relationship status, alcohol use and parity.

Regression analyses included women with complete data on exposure and outcomes of interest i.e. food consumption frequency, BMI $(n=963)$ and GWG $(n=746)$. Participants with missing data on food consumption frequency $(n=3 ; 0.3 \%)$, weight/height/GA for BMI calculation $(n=23 ; 2 \%)$ and second or third visit weight for GWG calculation ( $n=217 ; 22 \%)$ were excluded from the regression (Fig. 1). For confounders, missing data were included in the reference category as appropriate.

\section{Results}

The mean age of 989 participants enrolled was 29 years (SD \pm 6 ), gestational age at first ANC visit was 20 weeks (IQR, 14-25), 25\% of women were primigravid and $48 \%$ were living with HIV. The median BMI was $29 \mathrm{~kg} / \mathrm{m}^{2}$ (IQR, 24-34) overall; there were $21(2 \%)$ women with underweight, $273(28 \%)$ normal weight, 244 (25\%) overweight and $427(43 \%)$ obese BMI. Of the 427 women with obesity, 236 (46\%) were living without HIV and 191 (40\%) were living with HIV (Additional file 1). The median GWG was $0.36 \mathrm{~kg} /$ week (IQR, 0.14-0.54) overall, there were 266 (27\%) women with inadequate, 121 (12\%) adequate and 362 (37\%) excessive GWG. Of the 362 women with excessive GWG, 199 (39\%) were living without HIV and 163 (34\%) were living with HIV (Additional file 1).

Table 1 describes maternal baseline characteristics overall and stratified by HIV status, BMI and GWG categories. Women with HIV were more likely to be older and had higher parity compared to women without HIV, as were women with obesity compared to women with normal BMI. Women with excessive GWG were less likely to present early for their first ANC. Additional file 2 shows consumption frequencies of $30 \mathrm{food}$ items overall and stratified by HIV status, BMI and GWG categories; Fig. 2 shows selected food items stratified by HIV status only. The most frequently consumed ('4-7 days') starch was brown/whole wheat bread/rolls (58\%) and potatoes (any preparation) (53\%). Women with excessive GWG were more likely to consume potatoes for 4-7 days compared to those with adequate GWG ( $60 \%$ vs $47 \%, p=0.045)$. Of note, sweet potatoes (8\%) were the least consumed starch; women with obesity were more likely to report no consumption of sweet potatoes compared to women with normal BMI ( $84 \%$ vs 


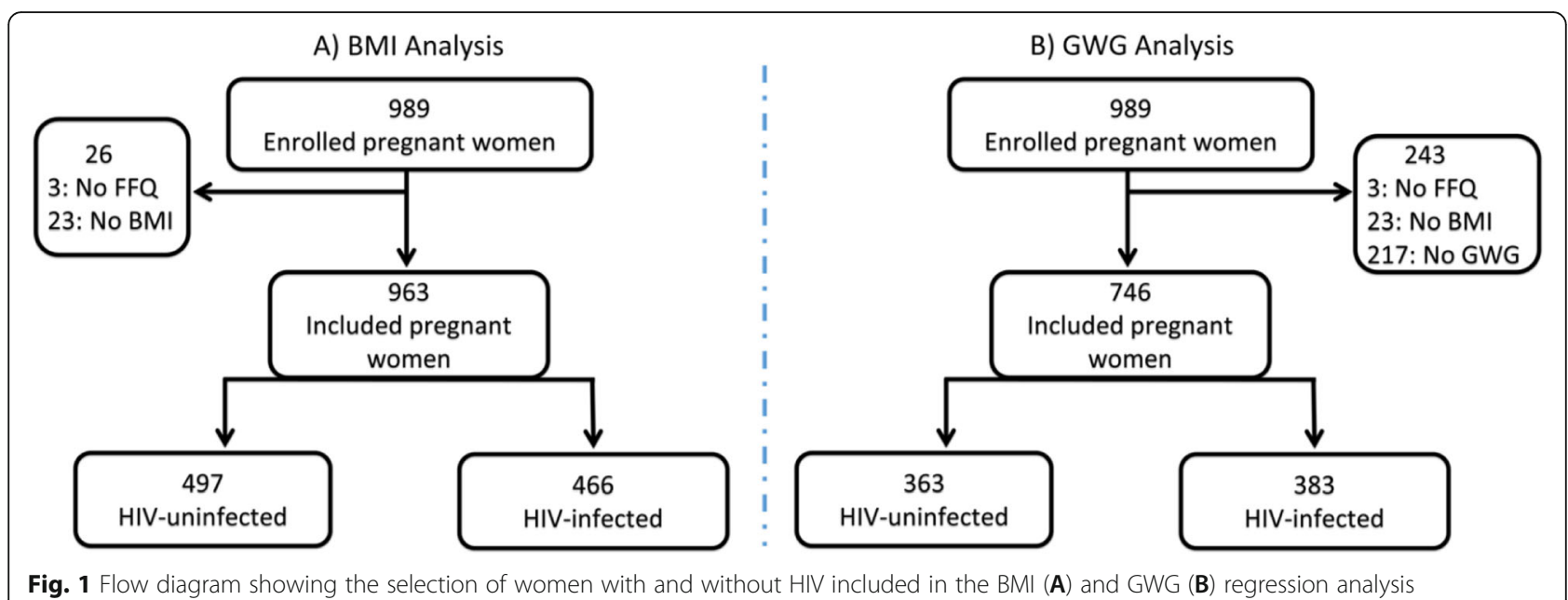

$76 \%, p=0.013)$. The most frequently consumed protein was chicken (48\%) and eggs (29\%); women with HIV were less likely to consume eggs for 4-7 days compared to women without HIV (25\% vs $33 \%, p=0.007$ ) (Fig. 2). Organ meat e.g. liver (13\%) and tinned fish (15\%) were the least consumed proteins. The most frequently consumed vegetable was carrots (35\%), with broccoli being the least $(5 \%)$. Women with obesity were more likely to report no consumption of broccoli ( $90 \%$ vs $82 \%, p=$ $0.019)$, but more likely to consume pumpkin/butternut (32\% vs $26 \%, p=0.028$ ) for $4-7$ days compared to women with normal BMI. Women with HIV were less likely to report no consumption of spinach ( $47 \%$ vs $54 \%$, $p=0.047$ ) and green beans ( $67 \%$ vs $74 \%, p=0.025)$ compared to women without HIV (Fig. 2). However, women with excessive GWG were more likely to report no consumption of spinach compared to those with adequate weight gain ( $56 \%$ vs $48 \%, p=0.026)$. Both legume items (baked beans/lentils [14\%]; peanuts/nuts [10\%]) were least consumed and this was similar by HIV, BMI and GWG categories.

Figure 3 shows the association between food intake frequency of selected items and overweight/obesity (A) and excessive GWG (B) in women without HIV (30 food items shown in Additional files 3 and 4). Consumption of potato (any preparation) (aOR 1.98, 95\% CI 1.023.84) and pumpkin/butternut (aOR 2.13, 95\% CI 1.293.49) for 1-3 days a week was positively associated with increased odds of overweight/obesity compared to not consuming any in the past week. Consumption of milk in tea/coffee (aOR 6.04, 95\% CI 1.37-26.50) for the same frequency was positively associated with increased odds of excessive GWG. In contrast, consumption of eggs (any) (aOR 0.52, 95\% CI 0.32-0.86) for 1-3 days a week was negatively associated with reduced odds of overweight/obesity, while peanut and nuts consumption for 4-7 days a week was negatively associated with reduced odds (aOR 0.34, 95\% CI 0.14-0.80) of excessive GWG compared to not consuming any in the past week.

Figure 4 shows the association between food intake frequency and overweight/obesity (A) and excessive GWG (B) in women with HIV (30 food items shown in Additional files 3 and 4). Consumption of milk/yoghurt/ maas to drink/on cereals (aOR 0.35, 95\% CI 0.18-0.68), tomato (raw/cooked) (aOR 0.50, 95\% CI 0.30-0.84), green beans (aOR $0.41,95 \%$ CI $0.20-0.86$ ), mixed vegetables (aOR 0.49, 95\% CI 0.29-0.84) and legumes e.g. baked beans, lentils (aOR 0.50, 95\% CI 0.28-0.86) for 47 days a week was negatively associated with reduced odds of overweight/obesity compared to not consuming any in the past week. Consumption of tomato (raw/ cooked) (aOR 0.48, 95\% CI 0.24-0.96) and mixed vegetables (aOR 0.38, 95\% CI 0.18-0.78) was also associated with reduced odds of excessive GWG compared to not consuming any in the past week.

\section{Discussion}

In this cohort we found that obesity during pregnancy and excessive GWG was common in both women living with and without HIV. Women without HIV who consumed potato (any preparation) and pumpkin/butternut for 1-3 days a week were more likely to be overweight/ obese; and milk in tea/coffee more likely to have excessive GWG. Further, those who consumed eggs (any) for 1-3 days a week were less likely to be overweight/obese; and peanut and nuts for 4-7 days a week less likely to have excessive GWG. Women with HIV who consumed milk/yoghurt/maas to drink/on cereals, tomato (raw/ cooked), green beans, mixed vegetables and legumes e.g. baked beans, lentils for 4-7 days a week were less likely to be overweight/obese. Further, those who consumed tomato (raw/cooked) and mixed vegetables for 4-7 days a week were less likely to have excessive GWG. Despite similar trends of obesity and GWG in women living 
Table 1 Maternal baseline characteristics of women included in the analysis, overall and stratified by HIV status, BMI and GWG category

\begin{tabular}{|c|c|c|c|c|c|c|c|c|c|c|c|c|}
\hline \multirow[b]{2}{*}{ Characteristic } & \multirow[b]{2}{*}{$\begin{array}{l}\text { Overall } \\
N \\
(\%)= \\
989\end{array}$} & \multicolumn{2}{|c|}{ HIV status } & \multirow[b]{2}{*}{$p$ value } & \multicolumn{3}{|l|}{ BMI } & \multirow[b]{2}{*}{$p$ value } & \multicolumn{3}{|l|}{ GWG } & \multirow[b]{2}{*}{$p$-value } \\
\hline & & $\begin{array}{l}\text { Without } \\
\text { HIV } \\
\mathrm{N}(\%)= \\
510\end{array}$ & $\begin{array}{l}\text { With } \\
\text { HIV } \\
N \\
(\%)= \\
479\end{array}$ & & $\begin{array}{l}\text { Normal } \\
\mathrm{N} \\
(\%)= \\
294\end{array}$ & $\begin{array}{l}\text { Overweight } \\
N(\%)=244\end{array}$ & $\begin{array}{l}\text { Obese } \\
N \\
(\%)= \\
427\end{array}$ & & $\begin{array}{l}\text { Inadequate } \\
\mathrm{N}(\%)= \\
266\end{array}$ & $\begin{array}{l}\text { Adequate } \\
\mathrm{N}(\%)= \\
121\end{array}$ & $\begin{array}{l}\text { Excessive } \\
N(\%)= \\
362\end{array}$ & \\
\hline Age (years) & & & & $<0.001$ & & & & $<0.001$ & & & & 0.077 \\
\hline$<24$ & $\begin{array}{l}240 \\
(24)\end{array}$ & $171(34)$ & $69(14)$ & & $\begin{array}{l}100 \\
(34)\end{array}$ & $58(24)$ & 79 (19) & & $48(18)$ & $30(25)$ & $100(28)$ & \\
\hline $25-29$ & $\begin{array}{l}292 \\
(30)\end{array}$ & $157(31)$ & $\begin{array}{l}135 \\
(28)\end{array}$ & & $93(32)$ & $71(29)$ & $\begin{array}{l}120 \\
(28)\end{array}$ & & $93(35)$ & $35(29)$ & $104(29)$ & \\
\hline $30-34$ & $\begin{array}{l}254 \\
(26)\end{array}$ & $109(21)$ & $\begin{array}{l}145 \\
(30)\end{array}$ & & $71(24)$ & $54(22)$ & $\begin{array}{l}123 \\
(29)\end{array}$ & & $75(28)$ & $34(28)$ & $81(22)$ & \\
\hline$\geq 35$ & $\begin{array}{l}203 \\
(21)\end{array}$ & $73(14)$ & $\begin{array}{l}130 \\
(27)\end{array}$ & & $30(10)$ & $61(25)$ & $\begin{array}{l}105 \\
(25)\end{array}$ & & $48(18)$ & $22(18)$ & $76(21)$ & \\
\hline Median (IQR) & $\begin{array}{l}29(25- \\
34)\end{array}$ & $\begin{array}{l}27(23- \\
32)\end{array}$ & $\begin{array}{l}31(26- \\
35)\end{array}$ & & $\begin{array}{l}27(23- \\
32)\end{array}$ & $29(25-35)$ & $\begin{array}{l}30(26- \\
34)\end{array}$ & & $29(26-33)$ & $29(25-33)$ & $\begin{array}{l}29(24- \\
33)\end{array}$ & \\
\hline Education & & & & 0.015 & & & & 0.870 & & & & 0.661 \\
\hline Primary & $37(4)$ & $15(3)$ & $22(5)$ & & $9(3)$ & $10(4)$ & $17(4)$ & & $9(3)$ & $4(3)$ & $17(5)$ & \\
\hline High school & $\begin{array}{l}929 \\
(94)\end{array}$ & 477 (94) & $\begin{array}{l}452 \\
(94)\end{array}$ & & $\begin{array}{l}277 \\
(94)\end{array}$ & $231(95)$ & $\begin{array}{l}399 \\
(93)\end{array}$ & & $252(95)$ & $113(93)$ & $334(93)$ & \\
\hline Tertiary & $23(2)$ & $18(4)$ & $5(1)$ & & $8(3)$ & $3(1)$ & $11(3)$ & & $3(1)$ & $4(3)$ & $10(3)$ & \\
\hline $\begin{array}{l}\text { Socio-economic } \\
\text { status }\end{array}$ & & & & 0.071 & & & & 0.602 & & & & 0.646 \\
\hline Lower & $\begin{array}{l}325 \\
(33)\end{array}$ & $152(30)$ & $\begin{array}{l}173 \\
(36)\end{array}$ & & $\begin{array}{l}105 \\
(36)\end{array}$ & $72(30)$ & $\begin{array}{l}136 \\
(32)\end{array}$ & & $87(33)$ & $45(37)$ & $119(33)$ & \\
\hline Middle & $\begin{array}{l}274 \\
(28)\end{array}$ & $142(28)$ & $\begin{array}{l}132 \\
(28)\end{array}$ & & $75(26)$ & $71(29)$ & $\begin{array}{l}123 \\
(29)\end{array}$ & & $81(31)$ & $35(29)$ & $96(27)$ & \\
\hline Higher & $\begin{array}{l}388 \\
(39)\end{array}$ & $215(42)$ & $\begin{array}{l}173 \\
(36)\end{array}$ & & $\begin{array}{l}113 \\
(38)\end{array}$ & $100(41)$ & $\begin{array}{l}168 \\
(39)\end{array}$ & & $96(36)$ & $41(34)$ & $144(40)$ & \\
\hline Missing & $2(0.2)$ & $1(0.2)$ & $1(0.2)$ & & $1(0.3)$ & $1(0.4)$ & 0 & & 0 & 0 & $2(0.6)$ & \\
\hline Relationship status & & & & 0.874 & & & & 0.001 & & & & 0.271 \\
\hline No relationship & $46(5)$ & $23(5)$ & $23(5)$ & & $13(4)$ & $11(5)$ & $22(5)$ & & $9(3)$ & $1(1)$ & $17(5)$ & \\
\hline $\begin{array}{l}\text { Not Cohabiting/ } \\
\text { married-NLT }\end{array}$ & $\begin{array}{l}509 \\
(51)\end{array}$ & $267(52)$ & $\begin{array}{l}242 \\
(51)\end{array}$ & & $\begin{array}{l}180 \\
(61)\end{array}$ & $124(51)$ & $\begin{array}{l}194 \\
(45)\end{array}$ & & $140(53)$ & $72(60)$ & $186(52)$ & \\
\hline $\begin{array}{l}\text { Cohabiting/ } \\
\text { married-LT }\end{array}$ & $\begin{array}{l}428 \\
(43)\end{array}$ & $218(43)$ & $\begin{array}{l}210 \\
(44)\end{array}$ & & $98(33)$ & $106(43)$ & $\begin{array}{l}211 \\
(49)\end{array}$ & & $114(43)$ & $48(400$ & $155(43)$ & \\
\hline Missing & $6(1)$ & $2(0.4)$ & $4(1)$ & & $3(1)$ & $3(1)$ & 0 & & $2(1)$ & 0 & $3(1)$ & \\
\hline${ }^{*}$ Alcohol use & & & & 0.982 & & & & 0.599 & & & & 0.227 \\
\hline No & $\begin{array}{l}898 \\
(91)\end{array}$ & $463(91)$ & $\begin{array}{l}435 \\
(91)\end{array}$ & & $\begin{array}{l}264 \\
(90)\end{array}$ & $218(89)$ & $\begin{array}{l}392 \\
(92)\end{array}$ & & $243(92)$ & $114(94)$ & $322(89)$ & \\
\hline Yes & $89(9)$ & $46(9)$ & $43(9)$ & & $29(10)$ & $25(10)$ & $35(8)$ & & $21(8)$ & $7(6)$ & $38(11)$ & \\
\hline Missing & $2(0.2)$ & $1(0.2)$ & $1(0.2)$ & & $1(0.3)$ & $1(0.4)$ & 0 & & $1(0.4)$ & 0 & $1(0.3)$ & \\
\hline $\begin{array}{l}\text { GA at first ANC } \\
\text { (weeks) }\end{array}$ & & & & 0.109 & & & & 0.455 & & & & 0.002 \\
\hline $\begin{array}{l}\text { 1st trimester } \\
(\leq 13)\end{array}$ & $\begin{array}{l}229 \\
(23)\end{array}$ & $109(21)$ & $\begin{array}{l}120 \\
(25)\end{array}$ & & $64(22)$ & $54(22)$ & $\begin{array}{l}110 \\
(26)\end{array}$ & & $74(28)$ & $39(32)$ & $64(18)$ & \\
\hline $\begin{array}{l}\text { 2nd trimester } \\
(14-28)\end{array}$ & $\begin{array}{l}609 \\
(62)\end{array}$ & $314(62)$ & $\begin{array}{l}295 \\
(62)\end{array}$ & & $\begin{array}{l}183 \\
(62)\end{array}$ & $160(66)$ & $\begin{array}{l}265 \\
(62)\end{array}$ & & $162(61)$ & $73(60)$ & $244(68)$ & \\
\hline $\begin{array}{l}\text { 3rd trimester (> } \\
\text { 28) }\end{array}$ & $\begin{array}{l}123 \\
(12)\end{array}$ & $73(14)$ & $50(10)$ & & $44(15)$ & $29(12)$ & $49(11)$ & & $28(11)$ & $8(7)$ & $51(14)$ & \\
\hline
\end{tabular}


Table 1 Maternal baseline characteristics of women included in the analysis, overall and stratified by HIV status, BMI and GWG category (Continued)

\begin{tabular}{|c|c|c|c|c|c|c|c|c|c|c|c|c|}
\hline \multirow[b]{2}{*}{ Characteristic } & \multirow[b]{2}{*}{$\begin{array}{l}\text { Overall } \\
N \\
(\%)= \\
989\end{array}$} & \multicolumn{2}{|c|}{ HIV status } & \multirow[b]{2}{*}{$p$ value } & \multicolumn{3}{|l|}{ BMI } & \multirow[b]{2}{*}{$p$ value } & \multicolumn{3}{|l|}{ GWG } & \multirow[b]{2}{*}{$p$-value } \\
\hline & & $\begin{array}{l}\text { Without } \\
\text { HIV } \\
N(\%)= \\
510\end{array}$ & $\begin{array}{l}\text { With } \\
\text { HIV } \\
\text { N } \\
(\%)= \\
479\end{array}$ & & $\begin{array}{l}\text { Normal } \\
N \\
(\%)= \\
294\end{array}$ & $\begin{array}{l}\text { Overweight } \\
N(\%)=244\end{array}$ & $\begin{array}{l}\text { Obese } \\
N \\
(\%)= \\
427\end{array}$ & & $\begin{array}{l}\text { Inadequate } \\
N(\%)= \\
266\end{array}$ & $\begin{array}{l}\text { Adequate } \\
\mathrm{N}(\%)= \\
121\end{array}$ & $\begin{array}{l}\text { Excessive } \\
N(\%)= \\
362\end{array}$ & \\
\hline Missing & $28(3)$ & $14(3)$ & $14(3)$ & & $3(1)$ & $1(0.4)$ & $3(0.7)$ & & $2(1)$ & $1(1)$ & $3(1)$ & \\
\hline Median (IQR) & $\begin{array}{l}20(14- \\
25)\end{array}$ & $\begin{array}{l}21(15- \\
26)\end{array}$ & $\begin{array}{l}19(13- \\
24)\end{array}$ & & $\begin{array}{l}21(14- \\
26)\end{array}$ & $20(14-23)$ & $\begin{array}{l}19(13- \\
24)\end{array}$ & & $19(13-24)$ & $18(12-22)$ & $\begin{array}{l}21(15- \\
25)\end{array}$ & \\
\hline Parity & & & & $<0.001$ & & & & $<0.001$ & & & & 0.690 \\
\hline 0 & $\begin{array}{l}251 \\
(25)\end{array}$ & $168(33)$ & $83(17)$ & & $\begin{array}{l}106 \\
(36)\end{array}$ & $51(21)$ & $86(20)$ & & $57(22)$ & $33(27)$ & $94(26)$ & \\
\hline 1 & $\begin{array}{l}331 \\
(33)\end{array}$ & $169(33)$ & $\begin{array}{l}162 \\
(34)\end{array}$ & & $92(31)$ & $89(36)$ & $\begin{array}{l}143 \\
(33)\end{array}$ & & $93(35)$ & $40(33)$ & $117(32)$ & \\
\hline$\geq 2$ & $\begin{array}{l}407 \\
(41)\end{array}$ & $173(34)$ & $\begin{array}{l}234 \\
(49)\end{array}$ & & $96(33)$ & $104(43)$ & $\begin{array}{l}198 \\
(46)\end{array}$ & & $114(43)$ & $48(40)$ & $150(42)$ & \\
\hline Median (IQR) & $1(0-2)$ & $1(0-2)$ & $1(1-2)$ & & $1(0-2)$ & $1(1-2)$ & $1(1-2)$ & & $1(1-2)$ & $1(0-2)$ & $1(0-2)$ & \\
\hline
\end{tabular}

* In current pregnancy. Married-NLT - Married but not living together, Married-LT - married and living together, GA - gestational age, ANC - antenatal care. BMI body mass index, GWG - gestational weight gain. Missing BMI 23 (2.4\%), GWG 240 (24.3\%)

both with and without HIV, positive associations with frequency of food intake were only observed in women without HIV. These data suggest that interventions targeted at modifying food-based dietary intake may play a significant role in reducing overweight/obesity and excessive GWG in pregnant women, particularly those living without HIV.

Obesity is a major public health concern in women as it has detrimental effects on women's health as well as that of their offspring $[7,10]$. The global nutrition transition, particularly increased consumption of an energy- dense diet, has been recognized as one of the major contributing factors to the constant rise in obesity. We found high consumption of potato (any preparation) in our cohort and this was associated with increased risk of overweight/obesity; women with excessive GWG were more likely to consume potato (any preparation) for 47 days a week compared to those with adequate GWG. Other authors have reported associations between starch and obesity noting that the nature of the relationship depends on the type of starch being consumed [25-27]. Starchy foods that are rapidly digestible (high-glycaemic
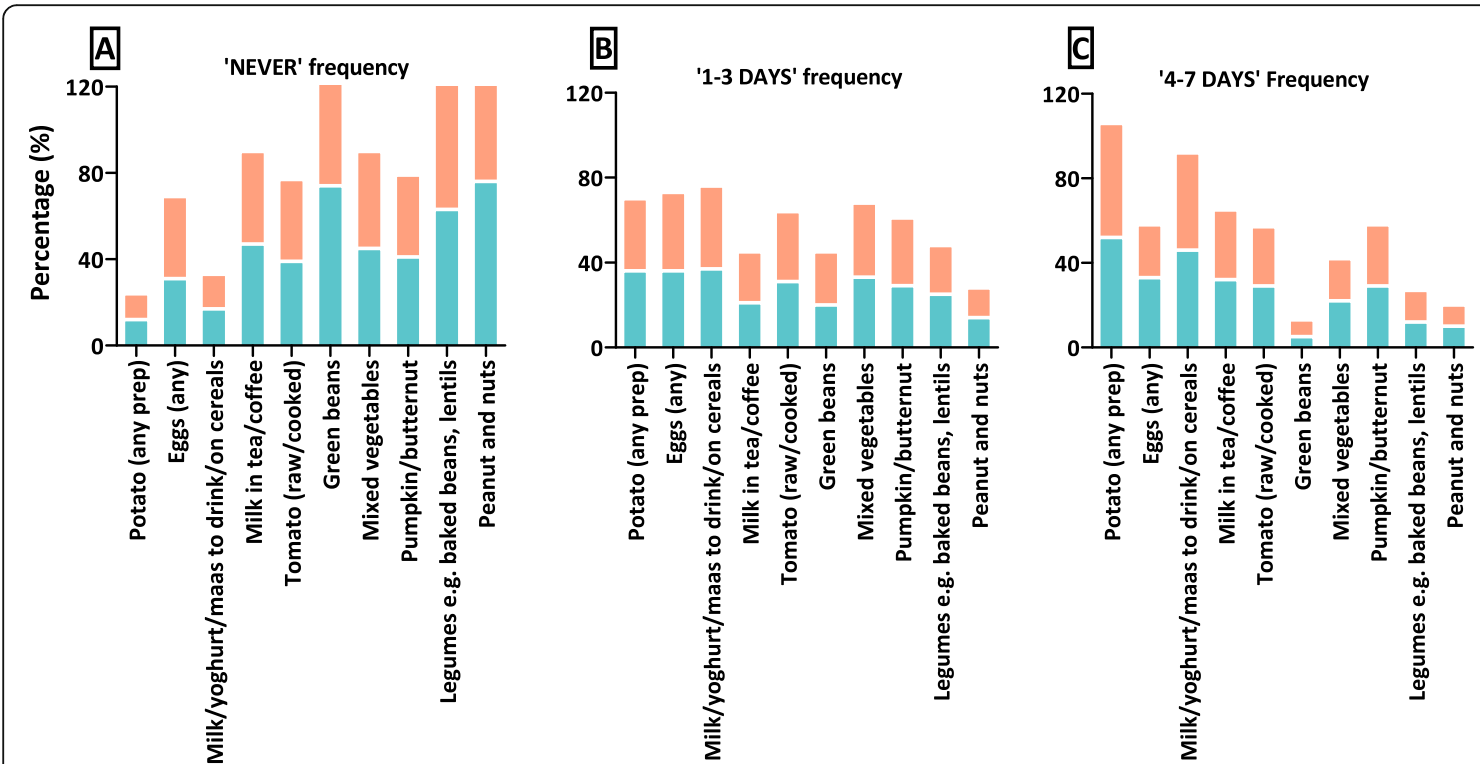

Fig. 2 Consumption frequencies of selected food items in women living with and without HIV for categories 'never' (A), '1-3 days' (B) and '4-7 days' (C) in the past week 

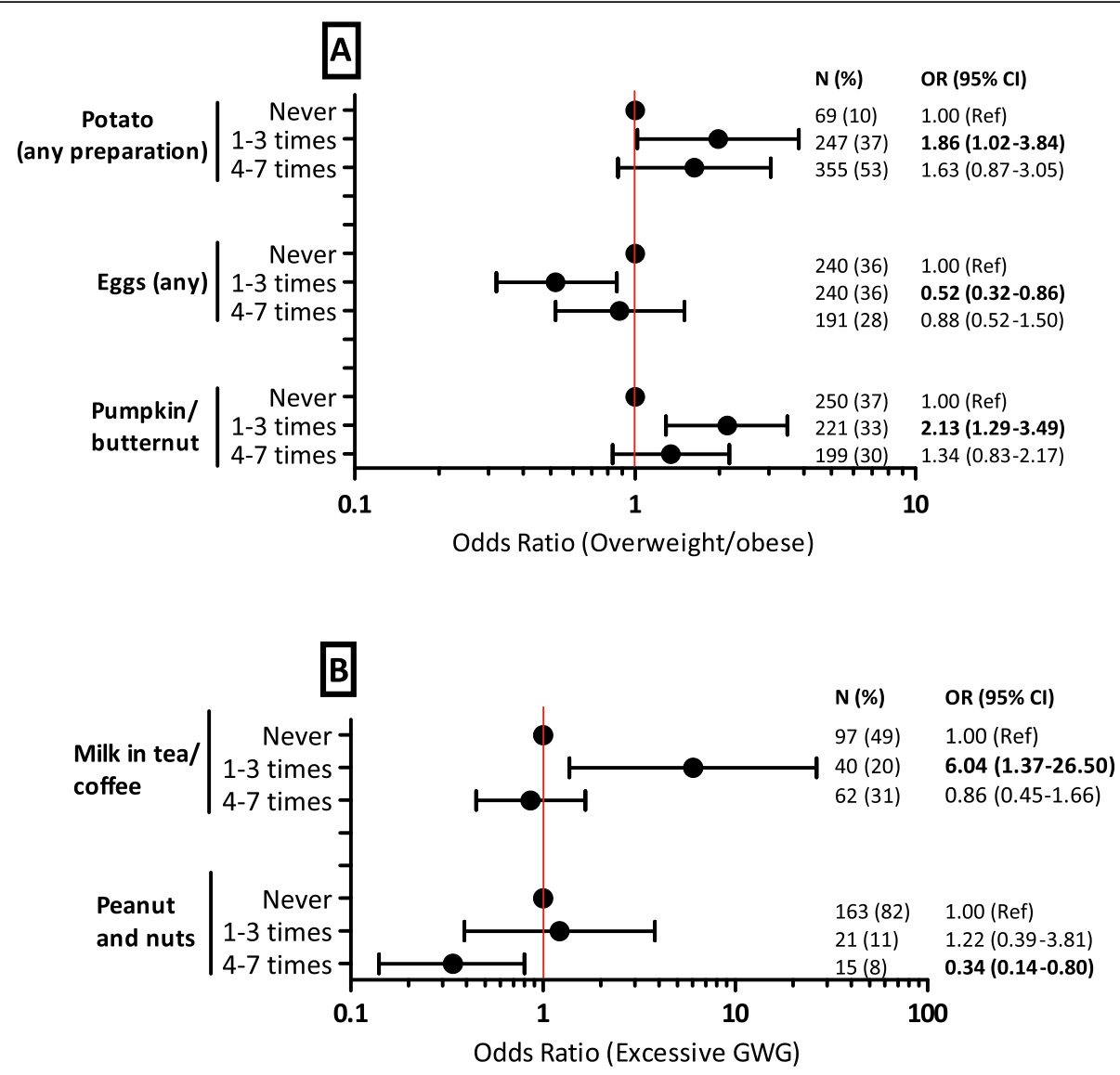

Fig. 3 Associations between food consumption frequency and overweight/obesity (A) and excessive GWG (B) in women without HIV

index) have worse health effects than those that are slowly digestible, as the former promote postprandial systemic hypoglycaemia accompanied by hunger and overeating [25, 26]. Potatoes have a high-glycaemic index $[28,29]$ and this may explain the mechanisms mediating the observed associations with overweight/obesity in women without HIV. In contrast, sweet potatoes have been shown to have protective effect against obesity due to their slow digestibility accompanied by sustained satiety [30, 31], however this food item was the least consumed starch in our cohort.

Vegetable consumption had more influence on maternal weight in women with HIV compared to those without. In particular, tomato (raw/cooked) and mixed vegetables decreased the odds of overweight/ obesity and excessive GWG in women with HIV; while green beans only reduced overweight/obesity. The importance of vegetables in the daily diet is highlighted in the Global Burden of Disease study which found that consumption of diet low in vegetables is among the leading dietary risk factors for mortality, contributing to more than $2 \%$ of global deaths [27]. Surprisingly in our study, women without HIV who consumed pumpkin/butternut for 1-3 days a week were more likely to be overweight/obese compared to those who did not consume any. Although not measured, we speculated that this was due to big portion sizes of pumpkin-containing dishes in this setting. This was shown in a study conducted in the Eastern Cape [32], a province from which most women in our cohort come from. Other scholars have reported controversial findings between vegetable consumption and weight, the study that used a 131-item semiquantitative FFQ found no association [33], whereas another study that used 3-item semiquantitative FFQ found a positive association [34]. Notably, vegetable consumption is most effective in maintenance or reduction of weight when it replaces the intake of high-energy dense foods [35], it remains unclear whether this was the case in our cohort as the FFQ used mainly consisted of healthy foods.

Consumption of eggs (any) in women without HIV, and legumes (baked beans, lentils) in women with HIV decreased the likelihood of overweight/obese. In addition, peanut and nuts decreased the odds of excessive GWG in those without HIV. Protein-rich diets, 

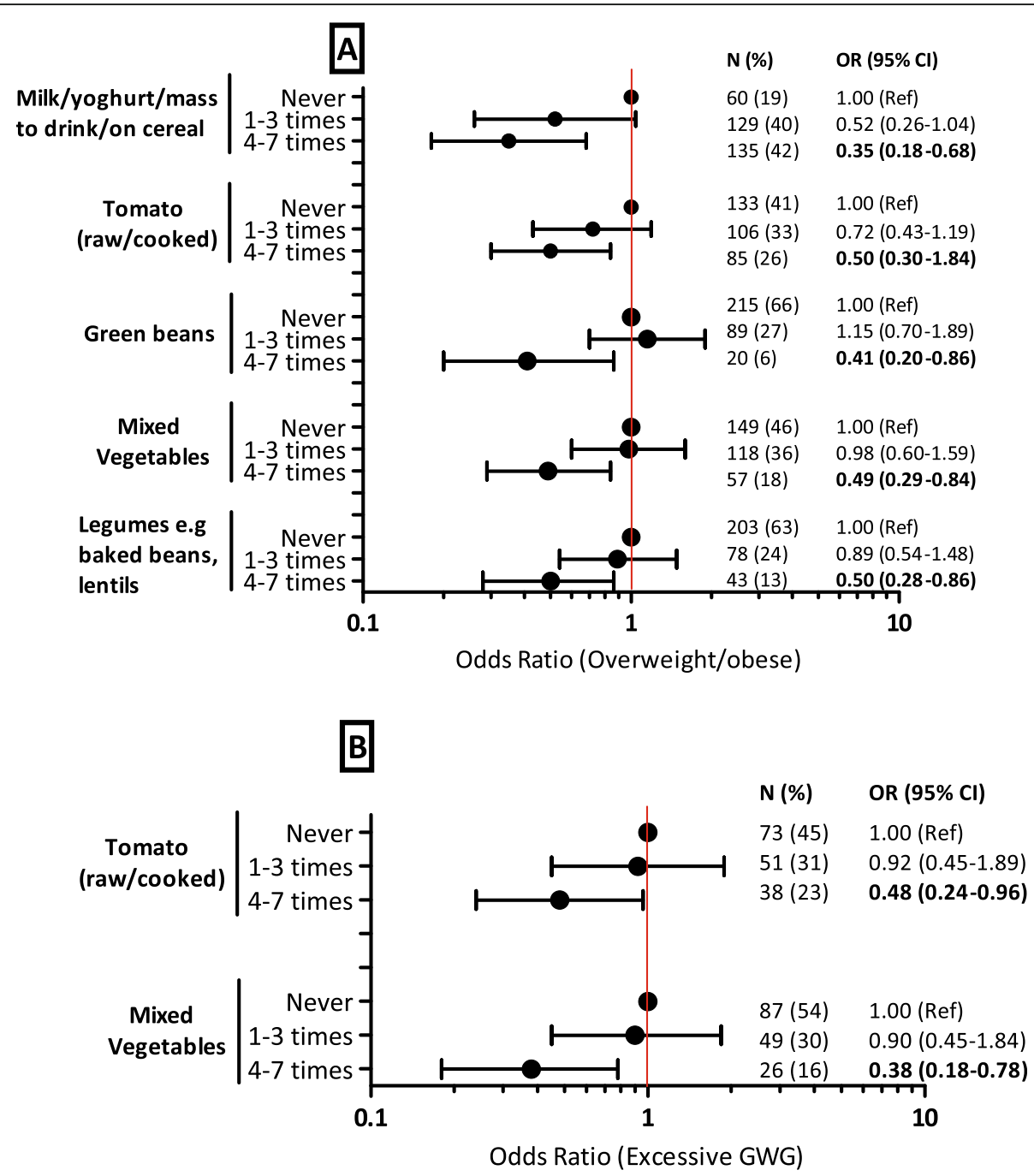

Fig. 4 Associations between food consumption frequency and overweight/obesity (A) and excessive GWG (B) in women with HIV

including legumes have been recommended for maintenance of healthy weight due to their high satiety effect (high fibre and low glycaemic index) which may favour energy intake control [36]. Specifically, several studies are in agreement with our results as they found that traditional diets containing legumes reduce the risk of excessive GWG, including having beneficial weight loss effects for those with obesity [37-39]. Dairy products, including milk have also been reported to have a negative association with weight in women who initially had normal weight [40]. In our study, we obtained similar results as women with HIV who consumed milk/yoghurt/ maas to drink/on cereals were less likely to experience excessive weight gain, however those without HIV who consumed milk in tea/coffee were more likely. These conflicting results warrant further study on the relationship between dairy products and maternal weight in settings where HIV is prevalent.
Despite similar consumption frequencies for potato, pumpkin/butternut and milk in tea/coffee in both women with and without HIV, positive associations with overweight/obesity and/or GWG were not observed in women with HIV, regardless of length of time on ART. This suggests that other than food intake, there may be factors influencing obesity and GWG in this group. Several studies reporting obesity in women with HIV attributed this trend to 'return to health' phenomenon as a results of access to early treatment due to international policy shifts; as well as exposure to the same obesogenic environment as others [41, 42]. However, factors specific to HIV infection and treatment regimens have also been implicated in influencing the vulnerability of people living with HIV to increased obesity [43]. Despite the growing number of studies reporting obesity in women with HIV in the general population [3, 5, 44, 45], there are limited data on GWG trends in this group. One 
South African study reported that women with HIV experience greater inadequate GWG [39], however, we found high prevalence of excessive GWG in our cohort. These differences may be partly attributed to a larger proportion of women who initiated ART pre-pregnancy in our cohort, enabling us to reflect recent trends in weight gain in these women.

Our data should be interpreted with caution since a chance of false-positives due to multiple testing conducted cannot be excluded. However, alpha correction approaches increase a chance of false-negatives due to very stringent significance levels. A non-quantitative FFQ was used and therefore quantity/exact consumption of foods reported was not assessed. Furthermore, the 30 food items investigated did not include some of the most common foods such as staple food maize meal. However, we were able to ascertain broader dietary intake trends that should be a key focus for future studies aimed at assessing quantity of food intake and obesity in pregnant women. In conclusion, potato (any preparation) and pumpkin/butternut consumption were associated with increased odds of overweight/obesity, while milk in tea/coffee consumption increased the odds of excessive GWG in women without HIV. Studies investigating potato (any preparation) and pumpkin/butternut portion sizes associated with obesity in pregnant women without HIV are needed. Mechanisms underlying high levels of obesity and GWG in women with HIV unrelated to food intake require further investigation.

\section{Supplementary Information}

The online version contains supplementary material available at https://doi. org/10.1186/s12889-021-11566-2.

Additional file 1. Frequencies of BMI $(\mathbf{A})$ and GWG (B) categories overall and stratified by HIV status.

Additional file 2. Frequencies of individual item food-based dietary consumption, overall and stratified by maternal HIV status, BMI and GWG category.

Additional file 3. Association between food consumption frequency and maternal BMI, overall and stratified by HIV status.

Additional file 4. Association between food consumption frequency and maternal GWG, overall and stratified by HIV status.

\section{Acknowledgements}

The authors thank participants, clinic staff at Gugulethu Community Health Clinic and staff members of "B positive" study.

\section{Authors' contributions}

$L M, A B, N P S, G P, M-A D$, EK, UM: study conceptualisation and design. HPM, DN, TRM: data collection, data analysis, data interpretation. HPM: literature search, generation of figures, writing of the manuscript. All authors reviewed, edited and approved the final manuscript.

\section{Funding}

Research reported in this publication was supported by the Eunice Kennedy Shriver National Institute of Child Health \& Human Development of the National Institutes of Health under Award Number R01HD080465. The content is solely the responsibility of the authors and does not necessarily represent the official views of the National Institutes of Health.

\section{Availability of data and materials}

All data generated or analysed during this study are included in this published article (and its supplementary information files). In addition, the datasets used and/or analysed during the current study are available from the corresponding author on reasonable request.

\section{Declarations}

Ethics approval and consent to participate

The study protocol was reviewed and approved by the Faculty of Health Sciences Human Research Ethics Committee of the University of Cape Town (REF 541/2015) and the Western Cape Department of Health (REF WC_2016RP6_286). Written informed consent was obtained from all participants at enrolment and all procedures complied with the Helsinki Declaration as revised in 1983.

\section{Consent for publication}

Not applicable.

\section{Competing interests}

The authors declare that they have no competing interests.

\section{Author details}

${ }^{1}$ Division of Epidemiology and Biostatistics, School of Public Health and Family Medicine, University of Cape Town, Falmouth Building, Anzio Road, Observatory, Cape Town, Western Cape 7925, South Africa. ${ }^{2}$ Division of Human Nutrition, Department of Human Biology, University of Cape Town, Cape Town, Western Cape, South Africa. ${ }^{3}$ Centre for Infectious Disease Epidemiology and Research, School of Public Health and Family Medicine, University of Cape Town, Cape Town, Western Cape, South Africa. ${ }^{4}$ Health Impact Assessment Unit, Western Cape Department of Health, Cape Town, South Africa. ${ }^{5}$ Department of Obstetrics and Gynaecology, University of Cape Town and New Somerset Hospital, Cape Town, Western Cape, South Africa.

Received: 26 November 2020 Accepted: 24 May 2021

Published online: 04 August 2021

\section{References}

1. South African Demographic Health Survey. Key Indicators Report 2016. Stats South Afr. 2017:1-76. https://dhsprogram.com/pubs/pdf/FR337/FR337.pdf.

2. Bakal DR, Coelho LE, Luz PM, Clark JL, de Boni RB, Cardoso SW, et al. Obesity following ART initiation is common and influenced by both traditional and HIV-/ART-specific risk factors. J Antimicrob Chemother. 2018;73(8):2177-85. https://doi.org/10.1093/jac/dky145.

3. Guehi C, Badjé A, Gabillard D, Ouattara E, Koulé SO, Moh R, et al. High prevalence of being overweight and obese HIV-infected persons, before and after 24 months on early ART in the ANRS 12136 Temprano trial. AIDS Res Ther. 2016;13(1):12-24. https://doi.org/10.1186/s12981-016-0094-y.

4. le Roux SM, Abrams EJ, Donald KA, Brittain K, Phillips TK, Nguyen KK, et al. Growth trajectories of breastfed HIV-exposed uninfected and HIVunexposed children under conditions of universal maternal antiretroviral therapy: a prospective study. Lancet Child Adolesc Health. 2019;3(4):234-44. https://doi.org/10.1016/S2352-4642(19)30007-0.

5. Madlala HP, Malaba TR, Newell ML, Myer L. Elevated body mass index during pregnancy and gestational weight gain in HIV-infected and HIVuninfected women in Cape Town, South Africa: association with adverse birth outcomes. Tropical Med Int Health. 2020;25(6):702-13. https://doi.org/1 $0.1111 /$ tmi.13387.

6. Kramer CK, Campbell S, Retnakaran R. Gestational diabetes and the risk of cardiovascular disease in women: a systematic review and meta-analysis. Diabetol. 2019;62(6):905-14. https://doi.org/10.1007/s00125-019-4840-2.

7. Lee KK, Raja EA, Lee AJ, Bhattacharya S, Bhattacharya S, Norman JE, et al. Maternal obesity during pregnancy associates with premature mortality and major cardiovascular events in later life. Hypertens. 2015;66(5):938-44. https://doi.org/10.1161/HYPERTENSIONAHA.115.05920.

8. Moussa HN, Alrais MA, Leon MG, Abbas EL, Sibai BM. Obesity epidemic: impact from preconception to postpartum. Future Sci OA. 2016;2(3): FSO137-48. https://doi.org/10.4155/fsoa-2016-0035. 
9. Howell KR, Powell TL. Effects of maternal obesity on placental function and fetal development. Reprod. 2017;153(3):R97-108.

10. Gaillard R. Maternal obesity during pregnancy and cardiovascular development and disease in the offspring. Eur J Epidemiol. 2015;30(11): 1141-52. https://doi.org/10.1007/s10654-015-0085-7.

11. Marchi J, Berg M, Dencker A, Olander EK, Begley C. Risks associated with obesity in pregnancy, for the mother and baby: a systematic review of reviews. Obes Rev. 2015;16(8):621-38. https://doi.org/10.1111/obr.12288.

12. Steyn NP, Mchiza ZJ. Obesity and the nutrition transition in sub-Saharan Africa. Ann N Y Acad Sci. 2014;1311(1):88-101. https://doi.org/10.1111/nya s.12433.

13. World Health Organisation. Diet, Nutrition and the Prevention of Chronic Diseases. Report of a Joint WHO/FAO Expert. Geneva: 2003. WHO Tech Rep Series no 916. ISSN 0512-3054. http://whqlibdoc.who.int/trs/WHO_TRS_916. pdf.

14. Kroll F, Swart EC, Annan RA, Thow AM, Neves D, Apprey C, et al. Mapping obesogenic food environments in South Africa and Ghana: correlations and contradictions. Sustain. 2019;11(14):3924-55. https://doi.org/10.3390/su11143 924.

15. Labadarios D, Steyn NP, Nel J. How diverse is the diet of adult south Africans? Nutr J. 2011;10(1):33-44. https://doi.org/10.1186/1475-2891-10-33.

16. Mchiza ZJ, Steyn NP, Hill J, Kruger A, Schönfeldt H, Nel J, et al. A review of dietary surveys in the adult south African population from 2000 to 2015. Nutr. 2015;7(June):8227-50

17. Ronquest-Ross L-C, Vink N, Sigge GO. Food consumption changes in South Africa since 1994. S Afr J Sci. 2015;111(9/10):1-12.

18. Kraschnewski $\mathrm{L}$, Chuang CH. "Eating for two": excessive gestational weight gain and the need to change social norms. Womens Health Issues. 2014; 24(3):e257-e9. https://doi.org/10.1016/j.whi.2014.03.004.

19. Audain K, Kassier S, Veldman F. Adolescent food frequency and socioeconomic status in a private urban and peri-urban school in Hilton, KwaZulu-Natal. South Afr J Clin Nutr. 2014;27(4):201-7. https://doi.org/10.1 080/16070658.2014.11734510

20. Sheehy T, Kolahdooz F, Mtshali TL, Khamis T, Sharma S. Development of a quantitative food frequency questionnaire for use among rural south Africans in KwaZulu-Natal. J Hum Nutr Diet. 2014;27(5):443-9. https://doi. org/10.1111/jhn.12166.

21. Myer L, Stein DJ, Grimsrud A, Seedat S, Williams DR. Social determinants of psychological distress in a nationally-representative sample of south African adults. Soc Sci Med. 2008;66(8):1828-40. https://doi.org/10.1016/j. socscimed.2008.01.025.

22. Santos S, Eekhout I, Voerman E, Gaillard R, Barros H, Charles MA, et al. Gestational weight gain charts for different body mass index groups for women in Europe, North America, and Oceania. BMC Med. 2018;16(1):20116. https://doi.org/10.1186/s12916-018-1189-1.

23. Gilmore LA, Redman LM. Weight gain in pregnancy and application of the 2009 IOM guidelines: toward a uniform approach. Obes. 2015;23(3):507-11. https://doi.org/10.1002/oby.20951

24. Institute of Medicine and National Research Council. Weight gain during pregnancy: reexamining the guidelines. Washington DC: National Academies Press; 2009. https://www.ncbi.n/m.nih.gov/books/NBK32813/.

25. Aller EE, Abete I, Astrup A, Martinez JA, MAv B. Starches, sugars and obesity. Nutr. 2011;3(3):341-69.

26. Englyst HN, Kingman S, Cummings J. Classification and measurement of nutritionally important starch fractions. Eur J Clin Nutr. 1992:46:S33-50.

27. Collaborators GD. Health effects of dietary risks in 195 countries, 1990-2017: a systematic analysis for the global burden of disease study 2017. Lancet. 2019;393(10184):1958-72

28. Borch D, Juul-Hindsgaul N, Veller M, Astrup A, Jaskolowski J, Raben A. Potatoes and risk of obesity, type 2 diabetes, and cardiovascular disease in apparently healthy adults: a systematic review of clinical intervention and observational studies. Am J Clin Nutr. 2016;104(2):489-98. https://doi.org/1 0.3945/ajcn.116.132332

29. Heidari-Beni M, Golshahi J, Esmaillzadeh A, Azadbakht L. Potato consumption as high glycemic index food, blood pressure, and body mass index among Iranian adolescent girls. ARYA Atheroscler. 2015;11(Suppl 1): $81-7$.

30. Shih C-K, Chen C-M, Hsiao T-J, Liu C-W, Li S-C. White sweet potato as mea replacement for overweight white-collar workers: a randomized controlled trial. Nutr. 2019;11(1):165-76.
31. Li G, Liu B, Zhang G, Zeng J, Sun J, Ma H. Characterization of digestion resistance sweet potato starch phosphodiester. Trop J Pharm Res. 2014; 13(9):1393-400. https://doi.org/10.4314/tjpr.v13i9.3.

32. Lombard M, Steyn N, Burger HM, Charlton K, Senekal M. A food photograph series for identifying portion sizes of culturally specific dishes in rural areas with high incidence of oesophageal cancer. Nutr. 2013;5(8):3118-30.

33. Rautiainen S, Wang L, Lee I-M, Manson JE, Buring JE, Sesso HD. Higher intake of fruit, but not vegetables or fiber, at baseline is associated with lower risk of becoming overweight or obese in middle-aged and older women of normal BMI at baseline. J Nutr. 2015;145(5):960-8. https://doi. org/10.3945/jn.114.199158.

34. Yu ZM, DeClercq V, Cui Y, Forbes C, Grandy S, Keats M, et al. Fruit and vegetable intake and body adiposity among populations in eastern Canada: the Atlantic Partnership for Tomorrow's health study. BMJ Open. 2018;8(4): e018060. https://doi.org/10.1136/bmjopen-2017-018060.

35. Kaiser KA, Brown AW, Bohan-Brown MM, Shikany JM, Mattes RD, Allison DB. Increased fruit and vegetable intake has no discernible effect on weight loss: a systematic review and meta-analysis. Am J Clin Nutr. 2014;100(2):56776. https://doi.org/10.3945/ajen.114.090548.

36. Larsen TM, Dalskov S-M, van Baak M, Jebb SA, Papadaki A, Pfeiffer AF, et al. Diets with high or low protein content and glycemic index for weight-loss maintenance. N Engl J Med. 2010;363(22):2102-13. https://doi.org/10.1056/ NEJMoa1007137.

37. Kim SJ, de Souza RJ, Choo VL, Ha V, Cozma Al, Chiavaroli L, et al. Effects of dietary pulse consumption on body weight: a systematic review and metaanalysis of randomized controlled trials. Am J Clin Nutr. 2016;103(5):121323. https://doi.org/10.3945/ajcn.115.124677.

38. Maugeri A, Barchitta M, Favara G, et al. Maternal dietary patterns are associated with pre-pregnancy body mass index and gestational weight gain: results from the "Mamma \& Bambino" cohort. Nutr. 2019;11(6):130819.

39. Wrottesley SV, Pisa PT, Norris SA. The influence of maternal dietary patterns on body mass index and gestational weight gain in urban black south African women. Nutr. 2017;9(7):732-46.

40. Rautiainen S, Wang L, Lee IM, Manson JE, Buring JE, Sesso HD. Dairy consumption in association with weight change and risk of becoming overweight or obese in middle-aged and older women: a prospective cohort study. Am J Clin Nutr. 2016;103(4):979-88. https://doi.org/10.3945/a jen.115.118406.

41. Bourgi K, Rebeiro PF, Turner M, Castilho JL, Hulgan T, Raffanti SP, et al. Greater weight gain in treatment-naive persons starting dolutegravir-based antiretroviral therapy. Clin Infect Dis. 2020;70(7):1267-74. https://doi.org/10.1 093/cid/ciz407.

42. Kumar S, Samaras K. The impact of weight gain during HIV treatment on risk of pre-diabetes, diabetes mellitus, cardiovascular disease, and mortality. Front Endocrinol. 2018;9:705-18. https://doi.org/10.3389/fendo.2018.00705.

43. Koethe JR, Lagathu C, Lake JE, Domingo P, Calmy A, Falutz J, et al. HIV and antiretroviral therapy-related fat alterations. Nat Rev Dis Primers. 2020;6(1): 48-67. https://doi.org/10.1038/s41572-020-0181-1.

44. Biggs C, Spooner E. Obesity and HIV: a compounding problem. South Afr J Clin Nutr. 2018;31(4):78-83. https://doi.org/10.1080/16070658.2017.1404299.

45. Tshikuka JG, Magafu MGMD, Rankgoane-Pono G, Mwita JC, Masupe T, Hamda SG, et al. Overweight and obesity among recipients of antiretroviral therapy at HIV clinics in Gaborone, Botswana: Factors Associated with Change in Body Mass Index. AIDS Res Treat. 2020;2020:1-8.

\section{Publisher's Note}

Springer Nature remains neutral with regard to jurisdictional claims in published maps and institutional affiliations. 